\title{
A NEW NEBRIA FROM MOUNT RAINIFR
}

\author{
By P. J. Darlington, JR.
}

An examination of the types of Nebria kincaidi Schwarz and $N$. columbiana Casey, which the authorities of the United States National Museum kindly permitted me to make recently, proves that the two species are absolutely identical. Schwarz's name has priority. This leaves the insect which has sometimes gone in collections as Nebria columbiana Casey without a name, so I propose that it be called

\section{Nebria vandykei sp. nov.}

Moderately stout, legs and antennæ slender. Color nearly uniform piceous or reddish piceous, but with the antennæ and parts of the under surface more or less rufescent; the head with two poorly defined reddish spots between the eyes; the elytra with weak purplish reflections. Head about five-sevenths as wide as the prothorax, eyes only slightly more prominent than the sides of the head behind them, antennæ more than one-half as long as the entire body. Prothorax about five-eighths as long as broad, strongly cordate, with the sides arcuate in anterior twothirds and reflexed before the acute posterior angles; prothoracic base and apex moderately emarginate, base about five-eighths as wide as widest part; pronotum only slightly convex, median longitudinal line narrow and well impressed, basal and apical transverse impressions variable but usually well impressed, lateral margins rather narrowly reflexed. Elytra about three and two-thirds times as long as the prothorax and one-third to two-fifths wider, elliptical, with the widest point behind the middle; humeri narrow, completely rounded into the sides as in Nebria ovipennis; striæ deep, very finely and rather sparsely punctured; intervals posteriorly with a few inconspicuous inter- 
ruptions. Inner wings only about one-third as long as elytra.

Length 10-13 mm. Width 4-5+ mm.

Holotype $\hat{o}$ and allotype $q$ in the writer's collection from Mount RAINIER, WASHIngton, near Paradise Valley, just below snow line at about 6000 feet elevation, July 18 and 13, 1927. A good series of paratypes from the same locality, July 13 to 20 . All specimens taken by the writer. There is some variation in the precise form of the basal angles of the prothorax and in the punctuation of the elytral striæ, but the species is not a particularly variable one.

As has been said, this is the Nebria which sometimes goes in collections as columbiana Casey. It belongs to the ovipennis group, but differs from ovipennis, its closest relative, in the submetallic lustre of the elytra and the much longer antennæ. It resembles also Nebria kincaidi Schwarz (columbiana Casey), but the latter is a. more convex and brilliant species, with a more strikingly cordate prothorax, with the elytral intervals more interrupted, and with more prominent eyes. It was probably Casey's failure to point out the last character in comparison with Nebria ovipennis Lec. which first led to the misidentification of his species. $N$. vandyke $i$ is obviously distinct from the other American species of Nebria with obliterated humeri (ingens Horn, spatulata V. Dyke, riversi V. Dyke, and lyelli V. Dyke), although I know riversi and lyelli only from descriptions.

I take great pleasure in naming this Nebria for Dr. Edwin C. Van Dyke, who has discovered and described so many fine species of the genus in western North America. 

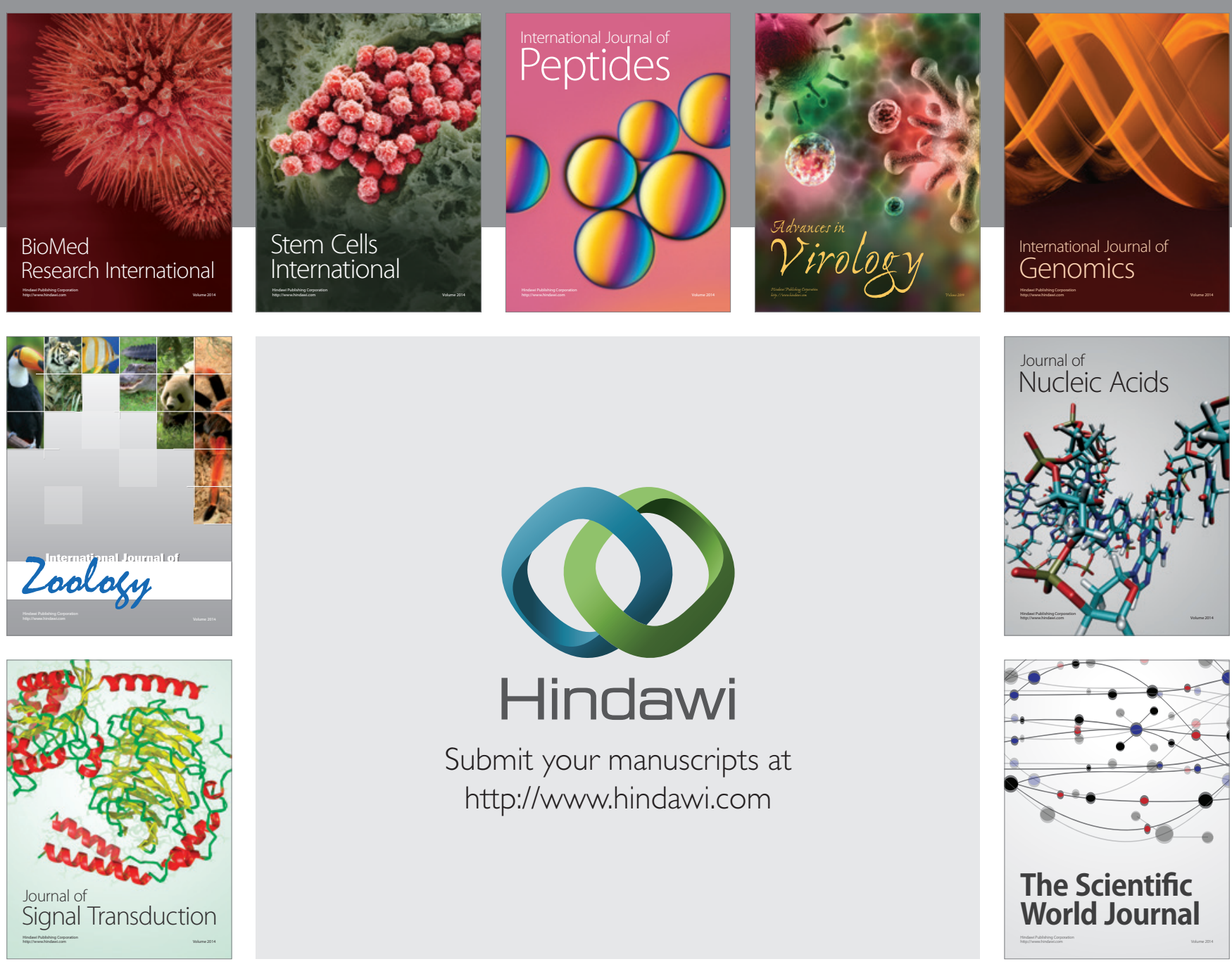

Submit your manuscripts at

http://www.hindawi.com
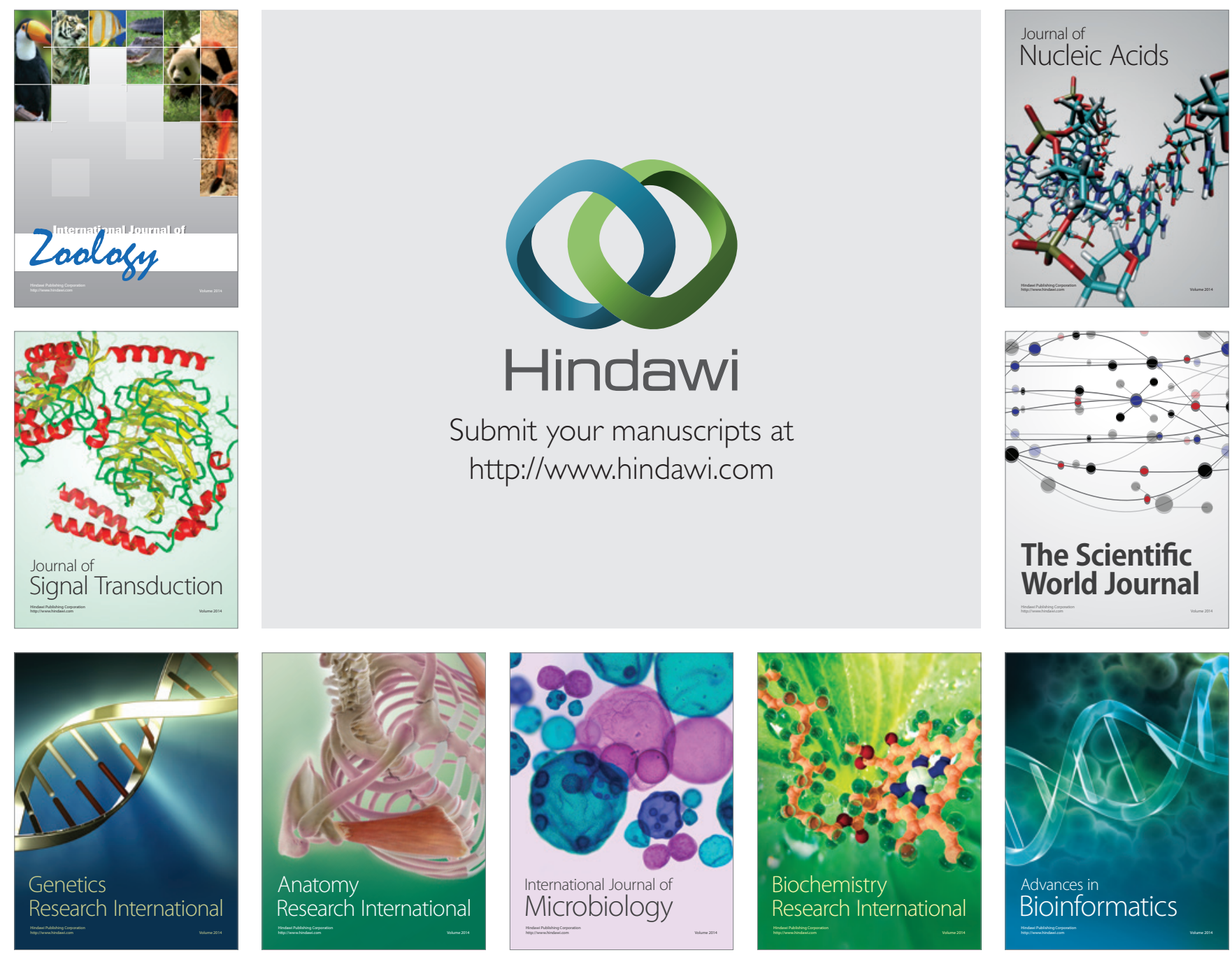

The Scientific World Journal
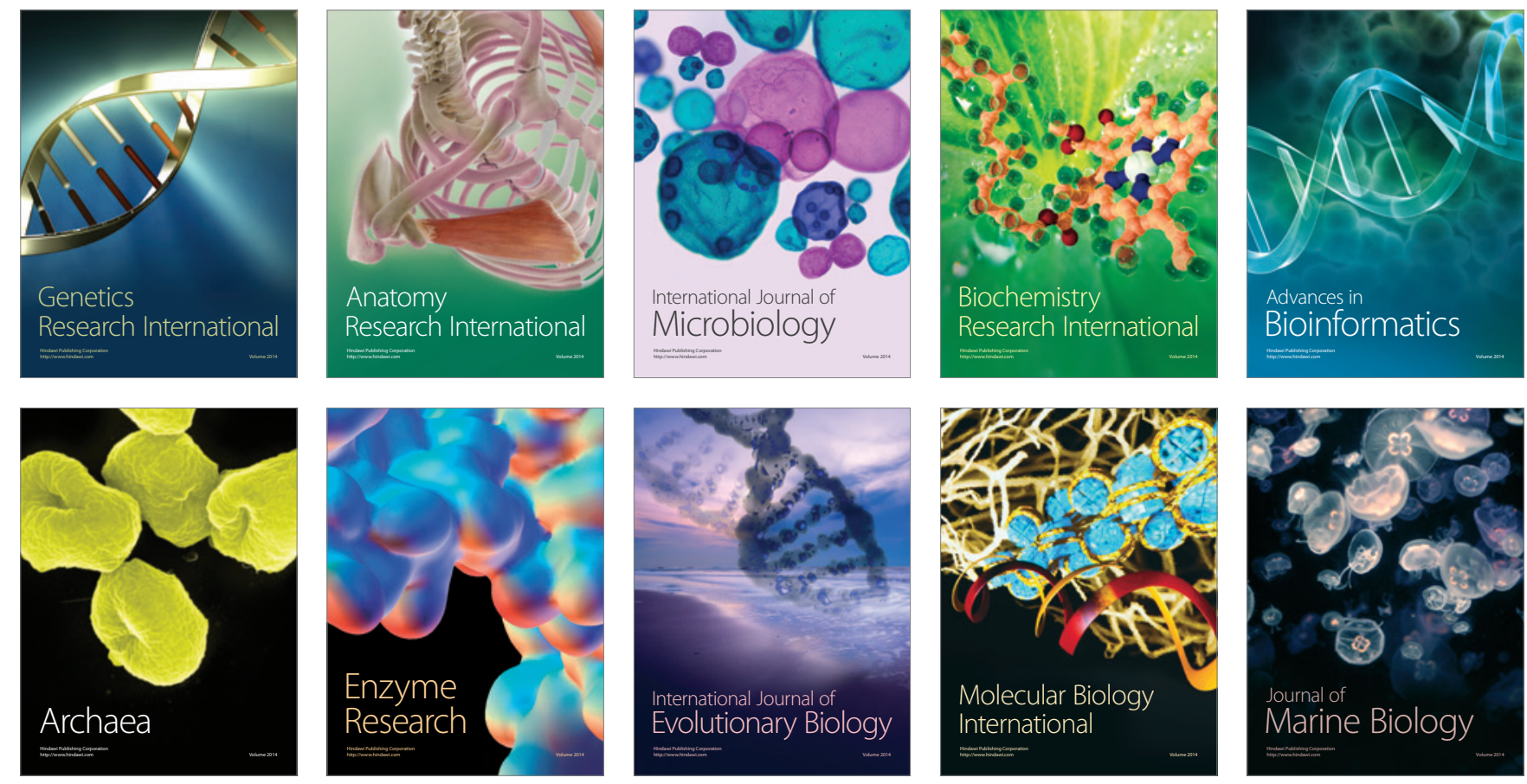